
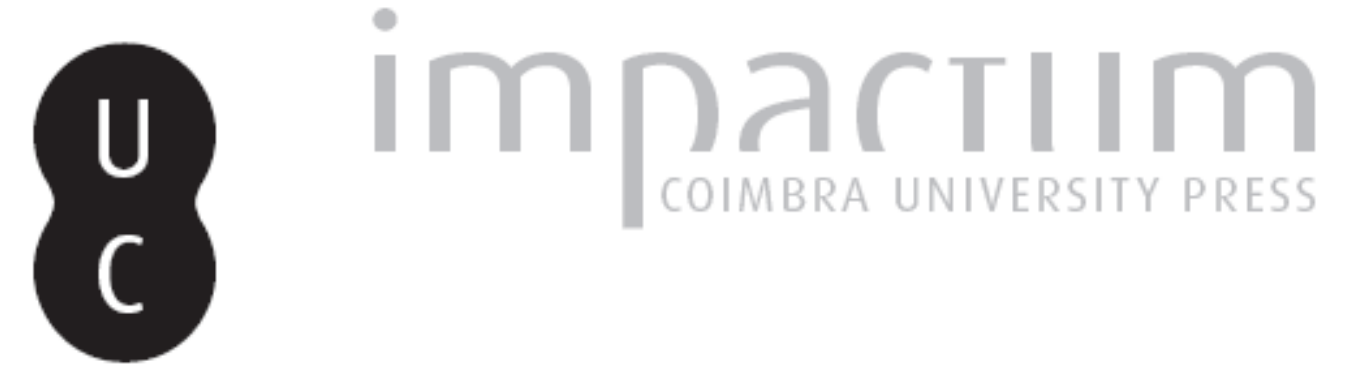

No trilho histórico do cancro: percepções de incurabilidade, invocações sagradas e
rejeição da medicina científica

Autor(es): $\quad$ Costa, Rui Manuel Pinto

Publicado por: Centro de História da Sociedade e da Cultura

URL persistente:

URI:http://hdl.handle.net/10316.2/39484

DOI:

DOI:http://dx.doi.org/10.14195/1645-2259_11_10

Accessed : $\quad$ 26-Apr-2023 05:23:09

A navegação consulta e descarregamento dos títulos inseridos nas Bibliotecas Digitais UC Digitalis, UC Pombalina e UC Impactum, pressupõem a aceitação plena e sem reservas dos Termos e Condições de Uso destas Bibliotecas Digitais, disponíveis em https://digitalis.uc.pt/pt-pt/termos.

Conforme exposto nos referidos Termos e Condições de Uso, o descarregamento de títulos de acesso restrito requer uma licença válida de autorização devendo o utilizador aceder ao(s) documento(s) a partir de um endereço de IP da instituição detentora da supramencionada licença.

Ao utilizador é apenas permitido o descarregamento para uso pessoal, pelo que o emprego do(s) título(s) descarregado(s) para outro fim, designadamente comercial, carece de autorização do respetivo autor ou editor da obra.

Na medida em que todas as obras da UC Digitalis se encontram protegidas pelo Código do Direito de Autor e Direitos Conexos e demais legislação aplicável, toda a cópia, parcial ou total, deste documento, nos casos em que é legalmente admitida, deverá conter ou fazer-se acompanhar por este aviso.

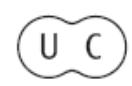




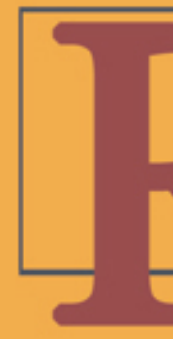

\section{evista de História} da Sociedade e da Cultura

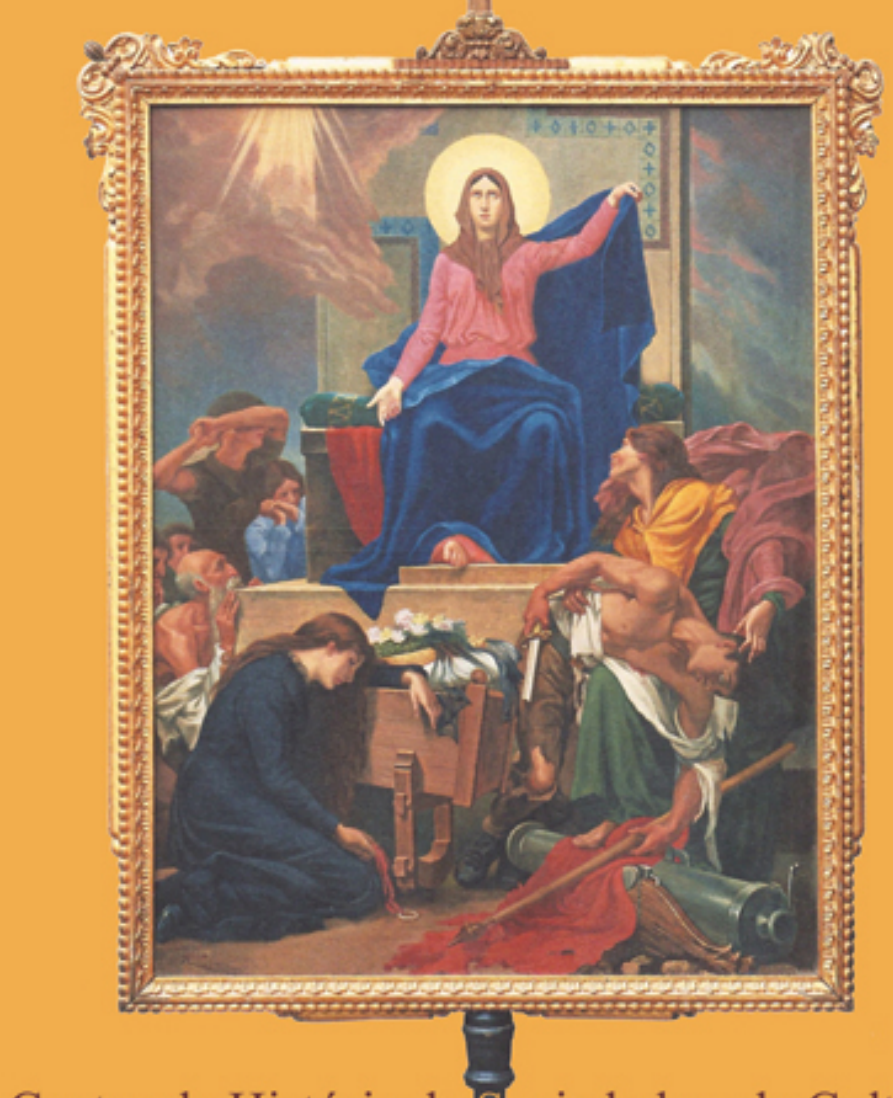

Centro de História da Sociedade e da Cultura Universidade de Coimbra 


\title{
No trilho histórico do cancro: percepções de incurabilidade, invocações sagradas e rejeição da medicina científica*
}

\author{
Rui Manuel Pinto Costa \\ CITCEM-FLUP (Centro de Investigação Transdisciplinar: Cultura, Espaço, Memória \\ - Faculdade de Letras da Universidade do Porto) \\ CEIS20 \\ rcosta75@gmail.comTexto recebido em/ Text submitted on: 08/10/2010 \\ Texto aprovado em/ Text approved on: 30/08/2011
}

\section{Resumo/Abstract:}

Enfermidade frustrante, tanto pela natureza insidiosa do seu crescimento, quanto pela proverbial resistência às tentativas terapêuticas da medicina científica, a compreensão humana sobre o cancro dependeu das crenças médicas sobre a natureza biológica dos tumores malignos, da ineficácia da terapêutica, e ainda dos valores, dor, sofrimento e modo como vemos o nosso próprio corpo. É o símbolo visível da mais angustiante percepção humana sobre a doença, cujas matrizes culturais mergulham no nosso passado mais recôndito. $\mathrm{O}$ presente artigo desenrola-se em redor da imemorial ideia de incurabilidade suscitada pela doença oncológica, patente nos séculos XVIII, XIX e ainda em meados do século XX, debruçando-se sobre alguns aspectos culturais que lhe são muito próprios.

Being a frustrating disease, as a result of the malignant nature of its growth and the resistance to the therapeutical attempts of scientific medicine, the human understanding of cancer depended on several aspects: the medical beliefs about the biological nature of neoplasmas, the ineffectiveness of medical treatments, and most of all, the atmosphere of suffering and pain. The present article approaches the immemorial idea of cancer incurability, present throughout the $18^{\text {th }}, 19^{\text {th }}$ and first half of the $20^{\text {th }}$ century, pointing out some particular cultural aspects that surround this disease.

Palavras chave/Keywords:

Cancro; Doença; Medicina.

Cancer; Disease; Medicine.

* Este artigo é um segmento narrativo de uma problemática mais extensa, sendo parte de um projecto de doutoramento onde o autor aborda historicamente a estruturação e normalização da luta contra o cancro em Portugal, entre meados do século XIX e o terceiro quartel do século XX. 
"O canceroso, como o tuberculoso, nunca faz ideia do seu estado; na véspera da terminação fatal da doença, tem ainda ilusões que causam a maior surpreza."1

José de Oliveira Lima, 1907

É interessante notar que, em larga medida, a egrégia visão hipocrático-galénica sobre a incurabilidade do cancro perdurou de tal forma nas mentalidades ao longo de tanto tempo, que mesmo nos dias de hoje há quem o considere à partida incurável, demorando por longo tempo a procura de tratamento médico adequado, mesmo quando este se encontra disponível.

No que à medicina científica concerne, desde a época moderna que tanto os doentes como os médicos inscreviam a sua compreensão do cancro num quadro comum, que, na sua essência, afectava o sujeito como um todo, mas que era sempre visto como singular, próprio de cada um e indissociável do indivíduo. A doença podia-se manifestar localmente, mas constituía a súmula ou a conjunção de vários problemas, que iam de defeitos constitucionais da pessoa, do seu património hereditário, dos seus hábitos alimentares, ou outros, conforme a explicação mais plausível para o médico. O diagnóstico passava pela observação dos sinais e apreciação dos sintomas mais evidentes, observáveis e passíveis de uma interpretação nem sempre igual, o que no caso dos cancros internos, raramente detectados, se tornava sumamente difícil e habitualmente impossível de realizar em vida. Este quadro perceptivo manteve-se até ao advento do século XIX.

A emergência da medicina hospitalar e a introdução do método clínico-anatómico permitiram um novo olhar médico sobre as doenças em geral e acerca do cancro em particular. A banalização do uso do microscópio permitiu observar as mudanças celulares nos tumores, desviando a atenção dos médicos para o campo celular. Em finais de oitocentos, a maioria não duvidava em catalogar o cancro como doença local, mas de consequências sistémicas. Se até então era habitualmente considerada uma maleita do indivíduo no seu todo, em finais do século XIX a atenção tinha-se deslocado para as manifestações locais da doença, e ainda para as células cancerosas

1 LIMA, José de Oliveira - O problema do cancro: etiologia e tratamento. Tese de doutoramento. Porto: Typ. a vapor de Arthur José de Souza \& Irmäo, 1907, p. 318. 
susceptíveis de constituírem a origem de novos crescimentos tumorais noutras regiões do corpo.

Neste contexto, o tratamento passava a ser não só do apanágio exclusivo do médico, mas sobretudo do bisturi do cirurgião, que dispunha das competências técnicas necessárias para o classificar cientificamente, mas sobretudo para o abordar na sua localização mais recôndita.

E se o pensamento médico dominante sobre a origem do cancro se foi alterando muito lentamente desde Hipócrates, num processo que durou milénios, tanto as possibilidades terapêuticas como a percepção humana negativa e terrificante da doença permaneceram invariavelmente as mesmas desde a antiguidade até ao século XIX, adentrando profundamente no século XX.

\section{A sinonímia da morte e o repúdio do incurável}

Em termos de discurso médico, a literatura científica de cada época caracterizava-o sempre com recurso a uma prosa invariavelmente sombria e de desfecho fatalista, visto enquanto mal terrível e quase sempre mortal. Os médicos reconheciam a doença, tentavam sistematizá-la, mas também declaravam abertamente a sua débil compreensão sobre a etiologia da mesma. Se os médicos gregos da antiguidade ligavam o cancro ao mundo aquático, lugar mítico de onde provinha o monstruoso e o inesperado, na Idade Média, Isidoro de Sevilha continuava a aceitar as mesmas premissas, definindo-o como uma praga incurável, que exigia uma intervenção cirúrgica apenas para prolongar ligeiramente a vida, ou quando muito, retardar por pouco tempo a morte aprazada. ${ }^{2}$

A impotência médica plasmada nos relatórios das observações clínicas dos doentes reflectem o sofrimento, a dor, e a inexorabilidade de um desfecho conhecido. São a imagem vibrante de uma doença que ultrapassava as

2 "Cancer a similitudine maritimi animalis vocatum vulnus (sicut medici dicunt) nulis medicamentis sanabili. Aut ergo precidi sole a corpore membrum, ubi nascitur, ut aliquanto diutius viuat: tamen inde mortem, quamlibet tardius affuturam. " In S. ISIDORI - Hispalensis Episcopi Hispaniarum Doctoris Opera Omnia. Romae: Typis Antonii Fulgonii, 1798, pp. 181-182. 
capacidades da medicina, e que, como tantas outras, se plasmava em prosa pungente, delineada nas mais gráficas descrições encontradas nos escritos médicos. Quando no século XVI Amato Lusitano referia que num dos seus doentes as "dores acompanhavam sempre esta chaga" e, por fim, foram "mais fortes e graves que nunca", é de ressalvar que este tipo de discurso angustiado e fatalista se manteve inalterado até ao tempo presente.

António Ferreira relata em 1705 um caso de cancro da mama inoperável, aludindo aos padecimentos da doente e à sua própria incapacidade para realizar qualquer tipo de abordagem cirúrgica ou remédio curativo:

“(...) manifestamente vejo, que o achaque, que esta senhora padece, ha hum cancro ulcerado, enfermidade taõ ruim, como trabalhosa, taõ cruel, como mortifera, (...) se tem alastrado, de modo que occupa a cintura, \& sovaco, sendo já total impedimento ao braço, ha já febre, e debilitaçoens de forças, (...) No estado em que ao presente está, naõ admitte esta [cirurgia], pois allem de naõ concorrerem as condiçoens ditas, naõ está capaz pela debilidade do sujeito, senão a paleativa, com que paleando se va dilatando a vida por mais annos."4

Em 1741, no seu Methodo facílimo e experimental para curar a maligna enfermidade do cancro, o cirurgião Anastácio da Nóbrega refere-se-lhe como sendo uma "(...) enfermidade tão fera, que à violencia de sua fúria parece impossivel escapar, o que por infortunio caiu em suas garras, podendo-se supor infeliz na possessão de tão desumano mal. É um ardiloso veneno, que entrando com suavidade a nascer, acaba com rigor a maltratar; e de sorte que se não contenta, sem que devore a mais preciosa prenda da saúde, e por conseguinte, sem que roube a mais estimável jóia da vida. ${ }_{5}$

No primeiro quartel do século XIX as diferenças de discurso médico não existem. Os relatos clínicos eram tão precisos nessa altura como o são hoje,

3 BRANCO, João Rodrigues de Castelo (Amato Lusitano) - Primeira Centúria de Curas Médicas. Trad. de Firmino Crespo. Lisboa: Livraria Luso-Espanhola, 1946, p. 113.

4 FERREIRA, António - Luz verdadeyra e recopilado exame de toda a cirurgia. Lisboa: na Officina de Valentim da Costa Deslandes, 1705, pp. 421 e 423.

5 NÓBREGA, Anastácio da - Methodo facílimo e experimental para curar a maligna enfermidade do cancro ... : dedicado ao senhor Francisco Teixeira Torres, Medico da camera de Sua Magestade... Lisboa Occidental: na Officina de Antonio Correa Lemos, 1741, p. 2. 
muito descritivos nas minudências e pormenores a que aludem, pintando quadros vivos de verdadeiro sofrimento humano. As fases avançadas são descritas como detalhe de um grafismo muito claro, algo que só um cirurgião habituado a esta doença consegue descrever; verdadeira medicina baseada na evidência sem necessidade de comprovação laboratorial do diagnóstico:

"Quando o cancro tem chegado a este grao, estende os seus destroços a toda a economia: as penas que o enfermo soffre, não lhe deixarão algum repouso; os tempos quentes e tempestuosos exasperão os seus males; a magreza he extrema, a pelle seca, e como terrosa; os ossos tornão-se frageis por perderem a sua geletina; as feições do rosto se altérão; e exprimem ao mesmo tempo a dôr fysica, e a deseperação; as glandulas linfaticas do interior se enfartão, e suppurão; a febre lenta acaba de consumir as forças já esgotadas por esta reunião de accidentes. Tal he o curso do cancro abandonado a si mesmo."

Em 1865, João de Lacerda relatava o caso de um doente com cancro do fígado internado no Hospital de Santo António, anotando:

"Dia 20 - Passou mal de noite com dôres no tumor, anciedade, e insomnia. Apresenta-se á hora da visita com respiração entrecortada, ancioso, pulso a 128, pequeno, duro; calor de pele muito exagerado. Localmente em volta da escara um circulo inflamatório, mais intenso do que se achava no dia antecedente. O tumor do mesmo volume. (...) Dia 27 - Morte à uma da manhã."”

Duas décadas mais tarde, Silva Carvalho descrevia com todo o pormenor os sofrimentos de uma doente portadora de cancro esofágico:

6 LEGOUAS, F. M. V. - Novos principios de cirurgia, resumidos das obras dos authores modernos conforme o plano do livro de G. de la Faye ... T. II. Lisboa: na Typografia Rollandiana, 1817, p. 320.

7 LACERDA, João Cesário de-Apontamentos para a descripção pathologica do cancro do figado. These apresentada e defendida em Julho de 1865. Lisboa: Imp. de J. G. de Sousa Neves, 1865, pp. 32- 33. 
"Continuei com o mesmo tratamento, aumentando a dose do brometo com que pretendia combater os espasmos do esófago, o estado de excitação em que se achava a doente e as insónias. O estado da doente agravava-se dia para dia (...) Em seguida a estas alterações do regimen [dieta alimentar] seguiam-se muitas vezes crises dolorosissimas em que a doente se rolava no leito com ansias enormes e vómitos que a deixavam muito extenuada. A disfagia foi aumentando mais e mais até que se tornou completa, as tentativas de engulir leite ou mesmo água simples tinham por único resultado aumentar-lhe os sofrimentos, sem proveito algum porque o líquido bebido era imediatamente deitado fora."

Os sintomas, por vezes vagos e negligenciados, levavam ao alongar da doença quantas vezes silenciosa, até ao momento em que mais nada se podia fazer. Este carácter potencialmente sub-reptício tornou-se característica quase indissociada do cancro oculto. O poeta e prosador alemão Theodor Storm, que morreu em 1888 de um cancro do estômago, descreveu o seu padecimento num pequeno poema intitulado o "Princípio do Fim" (Beginn des Endes):

"Uma picada! Uma dor ligeira!

Que nem sequer se sabe esclarecer,

Mas que tira o prazer da vida inteira,

Pois insistindo volta o seu doer!

Como queixar-me se o não sei dizer?

Com que palavras traduzir a queixa?

Sinto em meu âmago este meu sofrer

De um mal que existe, que já me não deixa!

${ }^{8}$ CARVALHO, Silva - "Revista clinica. Cancro do esophago. Alimentação durante muitos dias por meio de clysteres" A Medicina Contemporânea. (1887), 155. 
O mundo roda e tão velozmente

Como depressa se perdeu a esperança!

O mal começa e já não sai da mente

Que a negra foice toda a gente alcança!"’

O mesmo se pode depreender da descrição que António Elias faz da evolução do cancro esofágico, justificada pelo largo conjunto de sintomas que acabam por tornar penoso o prolongar da doença:

"Outras vezes o doente é atormentado por violentos accessos de suffocação ou por uma dyspnea violenta, (...) A fome e, sobretudo, a sede torturam o doente, e apparece uma salivação muito abundante; a cachexia accentua-se rapidamente, as dores exasperam-se, e o doente morre de inanição ou de cachexia cancerosa, quando alguma perfuração do appa-relho pulmonar ou circulatório não abrevia ainda mais os seus soffrimentos. (...) Depois de o cancro entrar em ulceração, a marcha da doença é geralmente rápida, e se algumas vezes apparece uma attenuação nos phenome-nos de dysphagia, esta é passageira e enganosa, significando apenas que houve deslocamento de alguma massa neoplasica, do que resulta um alargamento temporário no calibre do esophago. Quando assim é, as complicações graves (hemorrhagias, infecções bronchicas, pulmonares e pleuraes) não tardam a apparecer, tornando-se a morte imminente."10

Chegados a 1908, o tratamento paliativo era ainda, na maioria dos casos, a única resposta médica possível e eticamente aceitável para aqueles em estado avançado. De tal modo assim era que "Quando o tumor maligno (...) é inoperável ou quando o doente recusa a intervenção cirurgica, pode-se e deve-se utilisar o tratamento médico de maneira a calmar a dôr

9 Poema traduzido e transcrito em DIAS, Maria Teresa Furtado - O cancro do esófago e do estômago. Boletim do IPO. Vol 19. No 5 (1952) 10.

10 ELIAS, António Duarte Lima-Apertos do Esophago (Um caso clínico). Porto: 1902, pp. 41-42. 
e a levantar o estado moral. "11 Daí que a preparação dos doentes não fosse menosprezada, cabendo ao médico um papel importante na atenuação do impacto psicológico da doença em fase incurável:

"O medico nunca deve trahir pelo seu rosto o mínimo signal que a doente nunca possa desconfiar que está perdida. (...) Se a doente fálla de sorte deve-se tratar do assumpto mostrando-lhe que a doença é seria mas que pode viver durante muito tempo e que doentes declarados perdidos muitas vezes se têm curado. Se a doente apertar com muitas perguntas far-se-a calar pretextando que a fadiga de fallar lhe é altamente prejudicial. É preciso sempre convencer a doente que está attacada de uma-doença crónica para cuja cura o tempo concorre mais que as medicações, evitando sempre que dos seus lábios saia a pallavra incurável." 12

Nos anos 20 do século XX, o trabalho estatístico de Frederick Hoffman sobre o impacto social do cancro era citado com inusitada frequência, recolhendo-se do mesmo algumas frases lapidares que também serviram fins de propaganda anticancerosa. Ficou célebre uma expressão que utilizou ao definir a doença e o seu inexorável fim, ao referir que "A morte por cancro é o capítulo final de um drama horrível da vida humana."

Pela mesma altura, Marques dos Santos não duvida ao afirmar que "O canceroso morre no mais trágico abandono, embora se saiba que o seu mal é, por vezes, curável em determinadas circunstâncias (...)" ${ }^{\prime 14} \mathrm{Na}$ verdade, acontecia com o cancro o mesmo que se passava com a tuberculose, mas a matriz psicológica que a rodeava era substancialmente diferente, apesar do resultado final ser o mesmo.

${ }^{11}$ Notas clinicas e therapeuticas. Tratamento médico dos tumores malignos da larynge. Porto Médico $5^{\circ}$ Ano. No 9 (1908) 280.

${ }^{12}$ BORGES, Humberto Ferreira - Tratamento do cancro uterino inoperável. Dissertação inaugural apresentada à Faculdade de Medicina do Porto. Porto: 1911, pp. 58-59.

${ }^{13}$ Cartaz de propaganda do Instituto Português de Oncologia em 1935, reproduzindo a frase de Frederick Ludwig Hoffman.

${ }^{14}$ SANTOS, João Marques dos - A Luta Anti-Cancerosa em Portugal. (Conferência realizada em 26 de Fevereiro de 1925, na Associação dos Médicos do centro de Portugal). Coimbra: Imprensa da Universidade, 1925, p. 43. 
Esta carga psicológica, muito distinta e propiciadora da sua ocultação, encontra-se expressa de modo particularmente feliz nas palavras de Norberto Lopes, que em 1937 se indignava com a permanência de uma mentalidade diferenciada sobre o cancro face às demais doenças: "Porque se há-de ocultar o cancro, como se fosse uma doença censurável? Porque não pertence à categoria das doenças elegantes? Louvado Deus! Será mais elegante morrer de uma pneumonia que dum cancro?" 15

$\mathrm{Na}$ década de 30, o sofrimento das fases terminais leva alguns clínicos a contemplar e até a propor a possibilidade da eutanásia, ressalvando a inexorabilidade de um sofrimento geralmente atroz: "Como fazer o diagnóstico precoz de tal doença que caladamente se instala, e caladamente progride, evolucionando com maior ou menor rapidez para uma fatal generalisação inaccessivel à terapêutica actual, e cujos quadros finaes explicam, e nos fazem respeitar, os civilizados que aprovam e defendem a eutanásia de alguns dos povos selvagens?"16

No caso dos carcinomas metastizados, ulcerados e/ou supurantes, a cirurgia paliativa continuava a ser uma realidade nos anos 40, de tal modo que Francisco Gentil não deixa de a colocar como opção: "Quando não podemos curar temos o dever de diminuir o sofrimento e prolongar a vida, ainda que assim vamos criar condições para observar mais metástases a distância." ${ }_{17}$

A procura dos serviços médicos especializados, mesmo quando estes já existiam, eram propagandeados e funcionavam há muitos anos, não deixou de coexistir com uma mentalidade que receava recorrer aos médicos nas fases precoces da doença, o que não deixava de espantar um médico do Instituto Português de Oncologia em 1962:

${ }^{15}$ LOPES, Norberto - Tem dez anos de vida o instituto Português de Oncologia e inestimáveis serviços prestados à população e à ciência. Diário de Lisboa. (18 de Dezembro de 1937). In Boletim do IPO. Vol. 5. № 1 (1938) 8.

${ }^{16}$ BASTOS, Henrique - O cancro da próstata. A Medicina Contemporânea. Ano LI. No 13 (26 de Março de 1933) 84.

${ }^{17}$ GENTIL, Francisco - Conduta seguida na terapêutica do cancro genital pelo Instituto Português de Oncologia. Arquivo de Patologia. Vol. 20. № 2 (1948) 139. 
"É surpreendente a percentagem de doentes que recorrem ao IPO em estado terminal, sem possibilidade de fazer qualquer tratamento, mesmo a título paliativo. É grande o número de pessoas que comparecem nas consultas, portadores de tumores extensos, inoperáveis, sem qualquer possibilidade terapêutica. São doentes que referem muitas vezes o aparecimento de uma pequena ferida ou tumor, há meses, que tentaram tratar com os remédios locais, pomadas e injecções e que se mantém apáticos perante a evolução da doença, só procurando o médico ou o hospital quando sentem fugir-lhes as forças e a vida." 18

Talvez por isso Fernando Namora nos transmitisse um ao mais tarde uma ideia que sintetiza de forma tão subtil como acutilante o pensar da maioria da população portuguesa sobre o tema. Apesar da constante referência à doença na imprensa e dos esforços de uma propaganda não de pânico, mas de apelo à realidade, a luta contra o cancro ainda não criara um sentimento de defesa colectivo na mentalidade popular, muito simplesmente pelo facto de não ser uma doença com as características românticas como tinha sido a tuberculose:

"O cancro, hoje, dispondo de diferentes vias para se manifestar e de diferentes estímulos para sobreviver, é, sob muitos aspectos, um reflexo do ritmo tumultuoso, agressivo, traumatizante, que criámos e que interfere em quase todas as expressões da biologia. Daí, perdurar certa espécie de pessimismo, para não dizer irritação, em face das dúvidas, que o progresso científico ramifica, confessadas honestamente pelos investigadores, dúvidas que conduzem o homem da rua, ignorante mas atento, a concluir: nada se sabe sobre o cancro. (...) o público não se alista na nossa causa, que é de todos, porque o cancro não é uma doença romântica. Também as doenças precisam de uma auréola romântica quando se trate de impressionar multidões. O pavor, a repulsa, não bastam para congregar os que têm conhecimento do perigo. Pelo contrário: afastam-nos. Tem de haver uma reacção

${ }^{18}$ Uma entrevista ao Dr. Mário Vilhena. Boletim do IPO. Vol. 29. № 10 (1962) 6. 
emocionada, instintiva, qualquer coisa que inflame a veia lamecha do nosso temperamento. (...) O tuberculoso forneceu material para versos, para romances, para heróis, para suspiros. Teceu paixões, infortúnios e obras-primas. (...) Com a neoplasia, nada. É repelente e estéril. Que os cancerosos e os médicos resolvam, sem alardes, as suas agruras. São lá coisa dele. (...)"19

Mas o problema decorrente da necessária mudança de mentalidade não era apanágio exclusivo dos menos informados. Em 1964, Lima Basto apontava o dedo aos próprios médicos que também promoviam indirectamente a ideia de incurabilidade da doença, retardando o envio ao IPO de doentes eventualmente tratáveis:

"A nossa experiência em Lisboa, tem-nos mostrado que muitos médicos, depois de manterem em tratamento, ou sem ele, durante longos meses, doentes com a sua neoplasia, aguardam a fase terminal para os enviarem ao Instituto Português de Oncologia. Não estamos capacitados para fazer milagres." 20

Os peritos da OMS reforçaram esta ideia um ano mais tarde, ao aludirem à atitude dos que não investiam nos casos de doentes em estado avançado, em posição bem distinta da postura que assumiam ao "(...) cuidar atentamente de um doente cardiaco ou de um que sofra dos rins. É possível que uma tal atitude encontre as suas origens na longa e sinistra história do cancro (...) '21, doença que o tempo rotulou de incurável e à qual todos pretendiam fugir, até mesmo o próprio médico.

${ }^{19}$ NAMORA, Fernando - O romantismo, o público e as doenças. Boletim do IPO. Vol. 30. No 3 (1963) 1-3.

${ }^{20}$ Palavras de Lima Basto in "Posse das Comissões do Núcleo do Norte da Liga Portuguesa Contra o Cancro." Boletim do IPO. Vol. 31. N 11 (1964), 5-6.

21 "Os médicos não devem abandonar os casos de cancro." Boletim do IPO. Vol. 32 (1965), 3. 


\section{Invocações sagradas}

E se o discurso e respostas médicas continuaram a ser invariavelmente os mesmos, ao afectado apenas restava o recurso ao eventual apoio metafísico do sagrado. Por essa razão, o culto dos canonizados, com a atribuição de santos patronos a determinadas doenças, certamente mais ou menos prevalentes em determinados períodos históricos, serve para ilustrar o relevo dado às tribulações físicas do ser humano, que acaba por ter sempre uma inscrição muito clara nos domínios do sagrado. A invocação dos santos é um fenómeno muito disseminado, não apenas na tradição religiosa cristã, mas também noutras religiões. Contudo, o nível de "especialização" de alguns santos em doenças particulares, apenas atingiu um elevado grau de variedade e sofisticação no universo hagiológio católico.

Se bem que a frequência das doenças oncológicas ainda se pautasse pela relativa raridade até ao início do século XX, o medo e o sofrimento que despertava nunca deixaram de estar presentes, inscritos inclusive desde bem cedo no universo do mundo religioso. $\mathrm{O}$ culto dos santos protectores baseia-se em crenças sobre a sua influência benfazeja, na qualidade quer de advogados contra enfermidades e desaventuranças, quer de padroeiros e patronos. Estas concepções, que ultrapassaram a acção erosiva do tempo e a medicalização das populações pela medicina científica, ainda têm forte expressão nos nossos dias, sobretudo no mundo ocidental de matriz cultural judaico-cristã. O culto popular entre nós dos santos protectores ou advogados de enfermidades, estão documentados particularmente na importância que lhes é dada pelos clérigos nos múltiplos registos hagiográficos da cronística que chegou até nós. ${ }^{22}$

Neste sentido, é fácil compreender que Santa Ágata de Palermo, mártir cristã do século III à qual amputaram os seios, se tenha tornado a padroeira das doenças mamárias e em particular do cancro da mama. Na iconografia, a mártir é muitas vezes representada segurando uma bandeja com os dois peitos amputados. Um culto muito menos comum entre nós é o de

${ }^{22}$ A título de exemplo, veja-se a importância das hagiografias em COSTA, Rui Manuel Pinto; OLIVEIRA, Luís Alexandre de Sousa - A saúde do corpo e do espírito. Uma análise das crónicas dos eremitas de Santo Agostinho na sua vertente assistencial. Servir. Vol. No $54-\mathrm{N}^{\mathrm{o}} 6$ (2007) 264-273. 
São Ludgero, nascido na Frísia em 745, cuja invocação é preconizada contra os tumores da garganta. ${ }^{23}$

Do mesmo modo que São Francisco de Assis abraçava os leprosos num acto de amor cristão, mais tarde, no século XIV, Santa Catarina de Siena provara a sua caridade heróica ao recolher numa taça o sangue e pus do seio de uma mulher cancerosa, para de seguida o beber como se do sangue de Cristo se tratasse. ${ }^{24}$

O mesmo se pode dizer de um outro episódio em tudo semelhante no simbolismo revelado; na cerimónia do lava-pés, habitualmente realizado na Semana Santa, a rainha Isabel de Aragão, mulher de D. Dinis, e mais tarde canonizada como Rainha Santa, teria feito um milagre à portadora de um odorífero e pestilento cancro do pé. Apesar do "lastimoso espectáculo" para a visão, lavou-lhe o pé ulcerado, beijando de seguida a repelente chaga. ${ }^{25}$ Estes actos repulsivos, devem ser aqui entendidos como acções simbólicas que nos remetem para o sentimento de horror, sofrimento e repulsa associados à doença cancerosa: estigmatizante, repugnante, dolorosa, prolongada e invariavelmente fatal.

No domínio do sagrado, o cancro logrou, como tantas outras patologias, um lugar próprio, expresso na hagiografia, nas preces, ou inscrito na guarda de um santo protector. O caso de São Fiacrio, referido em pelo menos dois catálogos portugueses do século XVIII, enumeram-no como "advogado contra os cancros e almoleimas" (ou almorreimas), mostrando a habitual filiação doença/santo protector, tão característica do cristianismo católico. ${ }^{26}$ Mostra também a inclusão do cancro num rol alargado de outros "tumores",

${ }^{23}$ Cf. FREY, E. F. - Saints in medical history Clio Medica. Acta Academiae Internationalis Historiae Medicinae Amsterdam. Vol. 14. № 1 (1979) 35-70. Para uma visão teológica do culto dos santos na Igreja Católica, veja-se ainda MOLINARI, Paul - Saints: Their Place in the Church. New York: Sheed and Ward, 1965 e a sempre incontornável Bibliotheca sanctorum. (12 vols.) Roma: Instituto Giovanni XXIII nella Pontificia Università lateranense, 1961-70.

${ }^{24}$ Cf. BELL, R. M. - Holy Anorexia. Chicago: The University of Chicago Press, 1985.

${ }^{25}$ Cf. LACERDA, D. Fernando Correia de - História da vida, morte, milagres, canonização e trasladação de Santa Isabel, sexta rainha de Portugal. Lisboa: na Officina de António de Sousa da Sylva, 1785, p. 31.

${ }^{26}$ Cf. o manuscrito setecentista anónimo da BPMP n ${ }^{\circ}$ 569, intitulado "Santos Advogados contra os achaques e enfermidades do corpo humano" transcrito in SANTOS, Eugénio dos - O homem português perante a doença no século XVIII: atitudes e receituário. Revista da Faculdade de Letras. História. II Série. Vol. I. (1984) 199-201, e ainda o catálogo do padre oratoriano CARDOSO, Luis - Receita Universal ou Breve Noticia dos Santos Especiais 
fossem eles malignos ou benignos, como era o caso das almorreimas, que não são senão as comuns hemorróides, que sendo incomodativas, nada tinham de maligno.

Quando em meados do século XX o papa Pio XII proclama São Peregrino Laziozi como padroeiro dos cancerosos, verificamos que o faz num tempo em que a sociedade já havia despertado definitivamente para o problema da doença oncológica, e se encontrava em marcha um esforço internacional no sentido de combater e debelar o novo flagelo dos tempos modernos. A inclusão desta problemática num discurso de 1949, especialmente dirigido aos participantes na sétima semana de estudo sobre o problema biológico do cancro, é o exemplo acabado da importância social representada pela patologia cancerosa. ${ }^{27} \mathrm{~A}$ escolha de São Peregrino, que viveu nos séculos XIII e XIV, prendeu-se com o facto de o próprio ter sido alegadamente acometido de um cancro da perna, ${ }^{28}$ de odor intenso e ofensivo, em relação estreita com o ideário perpetuado ao longo do tempo sobre a doença oncológica. Mais recentemente, refira-se que a invocação de Santa Eufémia tomou, no tempo presente, o lugar de destaque como intercessor divino para os acometidos pelas doenças oncológicas, com maior expressão popular em algumas zonas do país, sobretudo na região norte e centro.

Contudo, e apesar de se encontrar inscrito no representativo culto dos Santos, dificilmente podemos encontrar uma grande mobilização social em face deste mal, senão a partir da última década de oitocentos. Apesar de constituir uma patologia genericamente encarada por todos como anatematizante, era um problema de saúde relativamente incomum, sem as características de rápida propagação, tão habituais nas doenças infecto-contagiosas, nem do elevado número de óbitos, tão frequentes nos fenómenos epidémicos. Episódio quase sempre pessoal, e muitas vezes inominável pelo seu habitual desfecho, o cancro permaneceu desde sempre

Advogados contra os achaques, doenças, perigos e infortúnios, a que ordinariamente vive sugeita a natureza humana. Lisboa Occidental: na officina de Joseph António da Sylva, 1727.

${ }^{27}$ Sobre os diferentes discursos de Pio XII dirigidos à comunidade médica veja-se BOLÉO, José de Paiva - Discursos de Pio XII aos médicos. Jornal do Médico. No 16 (5 de Abril de 1951) 129-130.

${ }^{28}$ Alguns historiadores acreditam que Laziozi sofria de veias varicosas e não de cancro. Cf. JACKSON, Robert - St. Peregrine, O.S.M - Patron Saint of Cancer Patients. Canadian Medical Association Journal. 111 (19 October 1971) 824-827. 
como problema de natureza individual, sem a dimensão colectiva e social que actualmente lhe atribuímos e que nos é familiar.

Um outro dado revelador do reduzido impacto social do cancro é a sua representação iconográfica nas artes visuais. Se ao longo dos séculos as diferentes dimensões visuais do corpo doente, da morte e das doenças, (fossem as do foro mental, da sífilis, da peste ou de outras epidemias) foram fonte de inspiração para numerosos trabalhos artísticos, muitos deles de natureza religiosa, o cancro não foi, nem de longe abordado com semelhante atenção.

Exceptuando as raras gravuras e ilustrações de alguns tratados médicos setecentistas e oitocentistas, ou mesmo as fotografias que desde finais do século XIX começam a ilustrar e documentar sistematicamente as doenças, os doentes ou os estados patológicos com intuitos científicos, aquilo que hoje poderíamos designar por iconografia oncológica foi coisa que não abundou. Daí que sejam muito raros e difíceis de encontrar na pintura ou sequer em gravuras os exemplos que aludem aos doentes afectados, ao tratamento, ou sequer a uma qualquer manifestação clínica.

Quando existem ou se conseguem identificar, constituem verdadeiros achados, e encontram-se ligados a momentos milagrosos que nos remetem para o papel da religião e do culto cristão dos Santos. ${ }^{29}$

A morte assumia muitas formas e tinha muitas causas, mas a doença oncológica não era mais significativa do que as demais. Morria-se de varíola e de disenteria como hoje se morre de velhice, isto é, como e quando Deus queria. E também de cancro. Com efeito, a doença só passa a existir enquanto fenómeno social, quando existem uma concordância na sua percepção, classificação e nas respostas que lhe são dadas. A sua aceitação exige que se estabeleça uma estrutura social específica para lidar com as arbitrariedades que ela origina, forçando uma reacção colectiva.

Para que tal pudesse acontecer, era necessário associar o cancro à noção de contagiosidade, algo que parece ter estado algo longe das concepções médicas sobre a doença. Apesar da natureza infecciosa dos tumores malignos

${ }^{29}$ Cf. um destes raros exemplos na obra do pintor renascentista Ambrosious Francken, in BERLE, E. J. - “"Miraculous Cancer Surgery' Iconography of a painting by the flemish painter Ambrosius Francken.” International Journal of Gynecological Cancer. Vol. 13 (March/ April 2003) 115-116. 
parecer evidente para alguns, as tentativas de inoculação animal do suco canceroso efectuadas por Peyrilhe em 1773, e depois por Dupuytren, Biett, Lenoble, Gluge, Valentin e Vogel, não obtiveram senão resultados completamente negativos. Por esta razão, no século XVIII e maior parte do XIX, a opinião corrente entre os médicos portugueses, reproduzindo aquela descrita na literatura médica francesa, ao tempo a mais seguida no nosso país, era a da não contagiosidade do cancro. Apesar de não haver provas científicas inequívocas, tal não significa que não continuasse a existir uma corrente subliminar do pensamento médico, que não descartava de todo o enquadramento da doença no âmbito infeccioso.

Doença ainda mal explicada e praticamente incurável, pode-se contudo entrever no discurso médico de finais de oitocentos uma real percepção médica e social sobre o cancro: a de que sua frequência parece começar a aumentar a partir da segunda metade do século XIX. Não nos esqueçamos que é também nesta altura que a esperança média de vida nos países ocidentais começa a configurar uma tendência mais positiva, e Portugal segue essa tendência demográfica.

\section{O cilício privado e a rejeição da medicina científica}

Os hospitais ou estabelecimentos pseudo-especializados no tratamento dos cancerosos parece nunca terem existido entre nós, ao contrário de algumas tentativas efémeras de pendor caritativo entretanto surgidas noutros países europeus ao longo do século XIX. Todas as fontes que consultámos são omissas nesse sentido, não nos revelando a existência de quaisquer hospitais nem sequer serviços especificamente adstritos a esse efeito em Portugal.

Os doentes oncológicos eram tratados em casa, a cargo das suas famílias, ou ainda num qualquer hospital sem a menor diferenciação relativamente à doença. A percentagem de curas era negligenciável e os doentes afectados necessitavam cuidados frequentes e prolongados. Quando muito, poderiam ser isolados, pelo odor e repugnância causada pelas eventuais "chagas cancrosas", mas não mais do que isso. Há ainda a considerar que existissem diagnósticos de cancro frequentemente incorrectos, confundidos com úlceras cutâneas, chagas sifilíticas, e quistos mamários benignos, o que repartiria 
ainda mais estes doentes pelas enfermarias comuns. No caso do denominado cancro visceral, a dificuldade era ainda maior, a atestar pelas dificuldades encontradas pelos médicos no correcto diagnóstico, por exemplo, do cancro do útero, do estômago ${ }^{30}$ ou do ovário, ${ }^{31}$ com sintomas por vezes semelhantes ou sobreponíveis a outras patologias não cancerosas. Habitualmente, a confirmação do diagnóstico inicial era feita apenas a posterori, ou seja, no momento da autópsia, ou aquando do exame histopatológico da peça cirúrgica excisada.

Nos hospitais ligados à Universidade, caso de Coimbra, ou às Escolas Médico-Cirúrgicas, caso de Lisboa e Porto, era essencialmente objecto de estudo clínico-anatómico, dando origem a apenas algumas poucas teses, muito menos do que aquelas saídas noutros países europeus, tanto em número absoluto quanto em percentagem comparativa com outras doenças.

Em relação directa com a dificuldade real do seu correcto diagnóstico, é certo que no final de oitocentos este problema associava-se à má fama de uma doença que mantinha a egrégia e sinistra reputação de ser maligna, dolorosa e mortífera.

Também por esta razão, não raro o próprio canceroso rejeitava o conselho do médico formado na universidade, em prol de uma qualquer solução menos invasiva que a cirurgia costumeira por vezes sugeria. Daí que o tratamento, como em tantas outras afecções humanas, fosse feito com o já habitual recurso a diferentes tipos de praticantes das "artes de curar", que incluíam curandeiros, charlatães e mezinheiros, costume este que parece ter sido muito comum tanto no Portugal rural quanto citadino dos séculos XVII e $\mathrm{XVIII} .{ }^{32}$ E pelo que se depreende das diferentes e frequentemente acrisoladas

${ }^{30}$ Cf. BARBA, Geraldes - Um caso de cancro do estômago. A Medicina Contemporânea. VI Ano. (1888) 186-188 e ainda GALRÃO, Carlos - O diagnóstico do cancro. A Medicina Contemporânea. VI Ano. No 29 (1888) 231-233, GALRÃO, Carlos - O diagnóstico do cancro (continuação) A Medicina Contemporânea. VI Ano. No 30 (1888) 239-241; Diagnostico differencial do cancro e da ulcera do estomago. A Medicina Contemporânea. VII Ano. (1889) 165-166.

${ }^{31}$ Cf. MAIA, Azevedo - Tumor ovarico. Operação. A Medicina Contemporânea. VI Ano. No 6 (1888) 78-82, e ainda SERRANO, J. A. - Tumor solido do ovario, do peso de 2150 gr. Laparotomia. Cura. A Medicina Contemporânea. VII Ano. № 27 (1889) 201-203, e SERRANO, J. A. - Tumor solido do ovario, do peso de 2150 gr. Laparotomia. Cura. (Continuação). A Medicina Contemporânea. VII Ano. No 28 (1889) 209-210.

${ }^{32}$ Cf. WALKER, Timothy D. - O papel e as práticas dos curandeiros e saludadores na sociedade portuguesa no início da idade moderna. História, Ciências, Saúde-Manguinhos, Vol. 11 (suplem. 1) (2004) 223-237; e ainda ARAÚJO, Maria Benedita - A medicina popular 
tentativas de defesa da medicina oficial, sem grandes sinais de abrandamento no decurso de todo o século XIX, ${ }^{33}$ o que estava em consonância, aliás, com o que se passava em várias capitais europeias onde campeavam uma série de especialistas na arte do engano, incluindo no tratamento do cancro, através do uso regular de emplastros, cataplasmas e drageias de origem pseudo-farmacológica.

Os exemplos desta realidade são-nos transmitidos por Filipe Simões nas suas crónicas insertas em 1859 no jornal $O$ Instituto, periódico científico conimbricense dedicado à divulgação das letras e ciências. Numa pequena série de artigos relatando as vicissitudes de um charlatão africano que tentara provar num reputado hospital parisiense a sua cura secreta do cancro, o autor acaba por expor uma realidade existente um pouco por toda a Europa:

"Desgraçadamente é grande a inclinação do espírito humano para os prodígios e maravilhas, e por isso a sciencia falsa, o charlatanismo e a impostura hão-de sempre achar gente crédula que se deixe enganar sem difficuldade. ${ }^{34}(\ldots)$ Os remédios infalliveis para tratar as úlceras cancrosas que d'antes eram sómente conhecidos de curandeiros obscuros, e de que apenas se ocupavam pessoas ignorantes e sem illustração, prendem agora a attenção das classes mais elevadas e instruídas da sociedade. (...) Diz-se que Londres é o paraízo dos charlatães, mas Paris a capital da França, o foco das Luzes, o centro das sciencias, parece aspirar também na actualidade ao mesmo epíteto." ${ }^{35}$

e a magia no sul de Portugal: contribuição para o estudo das correntes mentais e espirituais (fins do século XVII a meados do século XVIII). Tese de doutoramento. 3 Vols. Lisboa: Faculdade de de Letras da Universidade de Lisboa, 1988.

${ }^{33}$ Cf. CARVALHO, M. P. Henriques de - O clamor contra os flagicios, audacia e impostura dos charlatães e dos curandeiros: modo de os poder conter, reprimir e anniquilar. Lisboa: Typografia de V. J. De Castro \& Irmão, 1848.

${ }^{34}$ SIMÕES, A. Filipe - Juizo definitivo de Vriés e do tratamento secreto do cancro. O Instituto, Jornal Scientifico e Literario. Vol. 8. Coimbra: Imprensa da Universidade (1860) 26. (Apesar de datado de 1860, o volume 8 compila os números referentes aos periódicos publicados em 1859)

${ }^{35}$ SIMÕES, A. Filipe - Noticiario. Ainda o tratamento do cancro. O Instituto, Jornal Scientífico e Literario. Vol. 8. Coimbra: Imprensa da Universidade (1860) 61-62. 
Mesmo assim, se é de admitir que a medicalização progressiva das populações conduziu a um recurso cada vez menor dos serviços destes charlatães, ${ }^{36}$ eles mantiveram-se como parte não menosprezável das opções do público pelo adentrar do século XX, como se pode depreender das palavras do médico José de Pádua, deputado no Senado em 1911. Citando um caso da sua prática clínica, mostrava da seguinte maneira o seu desagrado pela falta de controlo estatal relativamente ao exercício ilegal da medicina:

"Há tempos foi consultar-me uma pobre criatura tendo 3 quartos da lingua devorada por um cancro, que se tinha já propagado ao pescoço onde formava um tumor das dimensões de uma maçã. Um mês antes tinha dado por uma pequena ferida na lingua; foi consultar um distintissimo cirurgião que lhe propôs a operação do cancro, por estar muito no início e localizado a uma pequena porção da lingua. A doente aterrou-se com a ideia da operação e teve a infelicidade de cair nas mãos de um curandeiro, que no fim de um mês, a pôs no estado em que a vi, e em que só tinha a esperar a morte pela impossibilidade de a operar então. Aqui está um curandeiro que num mês deu à doença uma rapidez de evolução, que ela não teria, abandonada a si mesma." ${ }^{37}$

Aparte o evidente antagonismo da classe médica para com os praticantes ilegais da arte de esculápio, problema que sempre acompanhou a prática médica e que persistiria durante a $\mathrm{I}^{\mathrm{a}}$ República, facilmente se infere a percepção clínica sobre a natureza terrífica da doença, e ainda o profundo impacto psicológico que a acompanhava. Apesar do afastamento progressivo das populações face ao curandeirismo confirmar a aceitação do carácter científico da medicina moderna, as respostas desta última eram ainda insuficientes ou quase nulas nos estados oncológicos avançados.

${ }^{36}$ Cf. a biobibliografia de médicos, curandeiros, charlatães e boticários que se dedicaram em Portugal à prática médica in CARVALHO, Augusto da Silva-Médicos e curandeiros. Lisboa: Tipographia Adolpho de Mendonça, 1917.

37 Diário do Senado. Sessão n ${ }^{\circ}$ 18, de 29 de Novembro de 1911, pp. 13-14. 


\section{Considerações finais}

Até finais do século XIX, a mobilização social determinada pela doença oncológica manteve-se praticamente a mesma que sempre foi perante qualquer doença de natureza não epidémica. Se algum interesse houve, foi proveniente de alguns médicos, sobretudo cirurgiões, o que mostra bem o seu protagonismo na única terapêutica anticancerosa realmente eficaz. A verdadeira tomada de consciência do perigo canceroso ainda não surgira no horizonte das preocupações sanitárias das sociedades, ou pelo menos ainda não lhes fora adequadamente instilada. Neste contexto, era a tuberculose que guardava ainda uma posição de predomínio quase absoluto no conjunto das preocupações sanitárias da medicina e da sociedade, expressa de forma bem viva nas diferentes e numerosas dissertações inaugurais das escolas médico-cirúrgicas de Lisboa e Porto, onde era tema predominante, quase impossível de não ser abordado todos os anos por uma parte considerável dos finalistas.

Seria necessário esperar pelas vozes de alarme dos profissionais de saúde e pelos investimentos em novos instrumentos tecnológicos de combate às neoplasias. Aguardar, pois, pelo dealbar da centúria seguinte, para assistirmos a uma mudança de tempo histórico onde a profissão médica se visse devedora de novos progressos tecnológicos, estudos estatísticos e de oncologia experimental, capazes de introduzir mudanças significativas no tratamento, e, claro está, de colocar a luta contra o cancro numa perspectiva social e colectiva.

\section{Fontes e bibliografia citada}

A Medicina Contemporânea (1888-1933)

Arquivo de Patologia (1948)

Boletim do Instituto Português de Oncologia (1938-65)

Diário do Senado (1911)

O Instituto, Jornal Scientifico e Literario (1860)

Bibliotheca sanctorum. (1961-70)

Porto Médico (1908) 
ARAÚJO, Maria Benedita - A medicina popular e a magia no sul de Portugal: contribuição para o estudo das correntes mentais e espirituais (fins do século XVII a meados do século XVIII). Tese de doutoramento. 3 Vols. Lisboa: Faculdade de de Letras da Universidade de Lisboa, 1988. BARBA, Geraldes - "Um caso de cancro do estomago". A Medicina Contemporânea. VI Ano (1888) 186-188.

BASTOS, Henrique - O cancro da próstata. A Medicina Contemporânea. Ano LI. No 13 (26 de Março de 1933) 84.

BELL, R. M. - Holy Anorexia. Chicago: The University of Chicago Press, 1985.

BERLE, E. J. - “ 'Miraculous Cancer Surgery` Iconography of a painting by the flemish painter Ambrosius Francken." International Journal of Gynecological Cancer. Vol. 13 (March/April 2003) 115-116.

BOLÉO, José de Paiva - Discursos de Pio XII aos médicos. Jornal do Médico. No 16 (5 de Abril de 1951) 129-130.

BORGES, Humberto Ferreira - Tratamento do cancro uterino inoperável. Dissertação inaugural apresentada à Faculdade de Medicina do Porto. Porto: 1911.

BRANCO, João Rodrigues de Castelo (Amato Lusitano) - Primeira Centúria de Curas Médicas. Trad. de Firmino Crespo. Lisboa: Livraria Luso-Espanhola, 1946.

CARDOSO, Luis - Receita Universal ou Breve Noticia dos Santos Especiais Advogados contra os achaques, doenças, perigos e infortúnios, a que ordinariamente vive sugeita a natureza humana. Lisboa Occidental: na officina de Joseph António da Sylva, 1727.

CARVAlHO, Augusto da Silva - Médicos e curandeiros. Lisboa: Tipographia Adolpho de Mendonça, 1917.

CARVALHO, M. P. Henriques - O clamor contra os flagicios, audacia e impostura dos charlatães e dos curandeiros: modo de os poder conter, reprimir e anniquilar. Lisboa: Typografia de V. J. De Castro \& Irmão, 1848. CARVALHO, Silva - Revista clinica. Cancro do esophago. Alimentação durante muitos dias por meio de clysteres. A Medicina Contemporânea. (1887).

COSTA, Rui Manuel Pinto; OLIVEIRA, Luís Alexandre de Sousa A saúde do corpo e do espírito. Uma análise das crónicas dos eremitas 
de Santo Agostinho na sua vertente assistencial. Servir. Vol. № $54-$ $\mathrm{N}^{\circ} 6$ (2007) 264-273.

DIAS, Maria Teresa Furtado - O cancro do esófago e do estômago. Boletim do IPO. Vol. 19. N 5 (1952) 10.

ELIAS, António Duarte Lima - Apertos do Esophago (Um caso clínico). Porto: 1902.

FERREIRA, António - Luz verdadeyra e recopilado exame de toda a cirurgia. Lisboa: na Officina de Valentim da Costa Deslandes, 1705.

FREY, E. F. - Saints in medical history. Clio Medica. Acta Academiae Internationalis Historiae Medicinae Amsterdam. Vol. 14. No 1 (1979) 35-70.

GALRÃO, Carlos - O diagnóstico do cancro. A Medicina Contemporânea. VI Ano. No 29 (1888) 231-233.

GALRÃO, Carlos - O diagnóstico do cancro (continuação). A Medicina Contemporânea. VI Ano. No 30 (1888) 239-241.

GENTIL, Francisco - Conduta seguida na terapêutica do cancro genital pelo Instituto Português de Oncologia. Arquivo de Patologia. Vol. 20. $\mathrm{N}^{\circ} 2$ (1948) 139.

JACKSON, Robert - St. Peregrine, O.S.M - Patron Saint of Cancer Patients. Canadian Medical Association Journal. 111 (19 October 1971) 824-827. JACQUEMET, G. - Médecine et maladies populaires dans le Paris de la fin du XIXe siècle. Recherches: L 'haleine des faubourgs (1978).

LACERDA, D. Fernando Correia de - História da vida, morte, milagres, canonização e trasladação de Santa Isabel, sexta rainha de Portugal. Lisboa: na Officina de António de Sousa da Sylva, 1785.

LACERDA, João Cesário de-Apontamentos para a descripção pathologica do cancro do figado. These apresentada e defendida em Julho de 1865. Lisboa: Imp. de J. G. de Sousa Neves, 1865.

LEGOUAS, F. M. V. - Novos principios de cirurgia, resumidos das obras dos authores modernos conforme o plano do livro de G. de la Faye ... T. II. Lisboa: na Typografia Rollandiana, 1817.

LIMA, José de Oliveira - O problema do cancro: etiologia e tratamento. Tese de doutoramento. Porto: Typ. a vapor de Arthur José de Souza \& Irmäo, 1907.

LOPES, Norberto - "Tem dez anos de vida o instituto Português de Oncologia e inestimáveis serviços prestados à população e à ciência." 
Diário de Lisboa (18 de Dezembro de 1937). In Boletim do IPO. Vol. 5. No 1 (1938) 8.

MAIA, Azevedo - Tumor ovarico. Operação. A Medicina Contemporânea. VI Ano. No 6 (1888) 78-82.

MOLINARI, Paul - Saints: Their Place in the Church. New York: Sheed and Ward, 1965.

NAMORA, Fernando - O romantismo, o público e as doenças. Boletim do IPO. Vol. 30. № 3 (1963) 1-3.

NÓBREGA, Anastácio da - Methodo facílimo e experimental para curar a maligna enfermidade do cancro.... dedicado ao senhor Francisco Teixeira Torres, Medico da camera de Sua Magestade... Lisboa Occidental: na Officina de Antonio Correa Lemos, 1741.

S. ISIDORI - Hispalensis Episcopi Hispaniarum Doctoris Opera Omnia. Romae: Typis Antonii Fulgonii, 1798.

SANTOS, Eugénio dos - O homem português perante a doença no século XVIII: atitudes e receituário. Revista da Faculdade de Letras. História. II Série. Vol. I. (1984) 199-201.

SANTOS, João Marques dos - A Luta Anti-Cancerosa em Portugal. (Conferência realizada em 26 de Fevereiro de 1925, na Associação dos Médicos do centro de Portugal). Coimbra: Imprensa da Universidade, 1925.

SERRANO, J. A. - Tumor solido do ovario, do peso de 2150 gr. Laparotomia. Cura. A Medicina Contemporânea. VII Ano. No 27 (1889) 201-203.

SERRANO, J.A. - Tumor solido do ovario, do peso de 2150 gr. Laparotomia. Cura. (Continuação). A Medicina Contemporânea. VII Ano. Nº $^{\circ} 8$ (1889) 209-210.

SIMÕES, A. Filipe - Juizo definitivo de Vriés e do tratamento secreto do cancro. O Instituto, Jornal Scientifico e Literario. Vol. 8. Coimbra: Imprensa da Universidade (1860) 26.

SIMÕES, A. Filipe - Noticiario. Ainda o tratamento do cancro. O Instituto, Jornal Scientífico e Literario. Vol. 8. Coimbra: Imprensa da Universidade (1860) 61-62.

WALKER, Timothy D. - O papel e as práticas dos curandeiros e saludadores na sociedade portuguesa no início da idade moderna. História, Ciências, Saúde-Manguinhos, Vol. 11 (suplem. 1) (2004) 223-237. 